\title{
Market Efficiency in Indian Exchange Rates: Adaptive Market Hypothesis
}

\author{
Dilip Kumar \\ Indian Institute of Management, Kashipur, India \\ Email: dksic212@gmail.com
}

How to cite this paper: Kumar, D. (2018) Market Efficiency in Indian Exchange Rates: Adaptive Market Hypothesis. Theoretical Economics Letters, 8, 1582-1598. https://doi.org/10.4236/tel.2018.89101

Received: March 7, 2018

Accepted: June 10, 2018

Published: June 13, 2018

Copyright $\odot 2018$ by author and Scientific Research Publishing Inc. This work is licensed under the Creative Commons Attribution International License (CC BY 4.0).

http://creativecommons.org/licenses/by/4.0/

\begin{abstract}
This paper utilizes the automatic variance ratio test and Belaire-Franch and Contreras (2004) rank-based tests to examine the adaptive market hypothesis in Indian exchange rates relative to US dollar (USD), Great British pound (GBP), Euro and Japanese yen (Yen). We use overlapping and non-overlapping moving subsample approach to examine the sensitivity of the results to a particular sample period. Our findings provide evidence in support of violation of the martingale hypothesis of Indian exchange rates relative to the US dollar and Japanese yen for whole sample period. Our findings also provide evidence that the predictability of returns of Indian exchange rates occurs from time to time and depends on occurrence of major macroeconomic events. These findings are consistent with the validity of adaptive market hypothesis in Indian exchange rates.
\end{abstract}

\section{Keywords}

Automatic Variance Ratio (AVR) Test, Rank-Based Tests, Adaptive Market Hypothesis (AMH), Market Efficiency, Return Predictability

\section{Introduction}

The foundation of the efficient market hypothesis lies in the ground-breaking works of Bachelier [1], Cootner [2], Samuelson [3] and Fama [4]. After the seminal studies of Samuelson [3] and Fama [4], the Efficient Market Hypothesis (hereafter EMH) has been one of the most important and widely documented theories in the finance literature. The theory of EMH states that if the market is efficient, then the asset prices fully reflect all the available information. This also reflects the inability to forecast future price changes using historical prices [4]. Moreover, the technical trading strategies are unprofitable if the market is efficient. This also indicates that the market movements follow a martingale 
process. Many studies in the literature related to the Efficient Market Hypothesis test whether the logarithmic price increments follow a martingale difference sequence (MDS), that is, no autocorrelation in the logarithmic price increments. If the Indian exchange rates follow MDS, then the Indian exchange rate returns are unpredictable using its own historical information. However, the inefficiency in the behavior of the exchange rates can be due to: 1) the intervention by the central bank [5]; 2) the exchange rate levels may not adjust quickly as new information hitting the market $[4] ; 3)$ the exchange rate may not be at the equilibrium level [6]; and 4) due to regulatory restrictions, the foreign banks may not be able to access the exchange rate market. The seminal work of Giddy and Dufey [7], Roll [8], Meese and Singleton [9], Adler and Lehmann [10], Darby [11], Hsieh [12] and Baillie and Bollerslev [13] provide evidence in support of the hypothesis that the nominal exchange rates follow a random walk. Huizinga [14] and Grilli and Kaminsky [15] find evidence against the random walk hypothesis for exchange rates.

Varieties of tests exist to analyze the efficiency characteristics of the time series. The most popular of all is the variance ratio test and its modifications. The variance ratio test was originally proposed by Lo and MacKinlay [16]. It assumes that if the given time series follows a random walk, then the variance of the $\mathrm{k}$-period return is $\mathrm{k}$ times of the variance of the one-period return. Various modifications of the variance ratio test exist in the literature which include Wright's [17] rank and sign tests, Choi's [18] automatic variance ratio test, Chow and Denning's [19] multiple variance ratio test, Whang and Kim's [20] multiple variance ratio test using sub-sampling, Belaire-Franch and Contreras's [21] rank and sign based variance ratio tests and Chen and Deo's [22] power transformed variance ratio test. The other kind of tests includes the autocorrelation test (Box and Pierce [23]; Ljung and Box [24]) and the spectral tests (Durlauf [25]; Hong [26]) to analyze the efficiency characteristics of the time series.

Literature provides evidence that the efficiency characteristics of the financial time series do not remain same over a period but exhibit time-varying property (Kumar and Maheswaran, [27]; Kumar, [28]; Kumar and Maheswaran, [29]). Lo [30] [31] proposed the concept of the adaptive markets hypothesis (AMH) which provides a framework to reconcile the market efficiency with the concept of bounded rationality. This indicates that the market efficiency characteristics do not remain same but vary with the changing market and macroeconomic conditions (recession, market crashes and crises, bubbles) and institutional factors. There exist two ways to examine the validity of the adaptive market hypothesis. The first way is to analyze the degree market efficiency by using time-varying models (Ito et al. [32] [33]). The second way is to analyze the market efficiency by using tests based on moving window approach (Kim et al., [34]; Lim et al., [35]).

The central aim of this paper is to analyze the market efficiency characteristics of the Indian exchange rates relative to US dollar, Great Britain pound, Euro and 
Japanese yen. The paper also analyzes the implication of changing market efficiency of the Indian exchange rates with respect to the adaptive market hypothesis. This paper uses the automatic variance ratio test proposed by Choi [18], in which the lag truncation point is chosen by the data-dependent method of Andrews' [36], and Belaire-Franch and Contreras tests [21] variance ratio test. These tests are completely data-dependent and do not require imposing any assumption on the underlying distribution. We have also used the overlapping and non-overlapping moving sub-sample approach to examine the implication of the adaptive market hypothesis in Indian exchange rates.

The remainder of this paper is organized as follows. Section 2 presents the relevant literature. Section 3 describes the methodology used. Section 4 describes the data and computational procedure. Section 5 reports the empirical results and Section 6 concludes with a summary of our main findings.

\section{Literature Review}

There exist numerous studies about the efficient market hypothesis in the foreign exchange rates with mixed results. Huizinga [14] and Grilli and Kaminsky [15] find evidence against the efficient market hypothesis for exchange rates. Liu and $\mathrm{He}$ [37] observe the rejection of the efficient market hypothesis for five pairs of nominal exchange rates based on the Lo and MacKinlay [16] variance ratio tests. Fong et al. [38] test the martingale behavior of exchange rates using joint variance ratio tests and find mixed results. Choi [18] tested the weak form efficiency of the US real exchange rates using automatic variance ratio test, spectral domain tests and average exponential tests on log-differenced monthly US real exchange rates versus some major currencies and finds mixed results. Wright [17], Yilmaz [39] and Chang [40] analyze the efficient market hypothesis in five exchange rates (Great British pound, Japanese yen, Canadian dollar, Swiss franc and Deutschemark) using various variance ratio tests. Chang [40], using daily data, finds the evidence of rejection of martingale difference hypothesis for the Japanese yen. However, the results for the Great British pound, Canadian dollar, Swiss franc and German mark are inconclusive. Belaire-Franch and Opong [41] use rank and sign variance ratio tests to examine the behavior of Euro exchange rates, with the p-values being adjusted by the Sidack correction and bootstrap correction procedure. The results support the rejection of weak form market efficiency for Euro exchange rates. However, Charles and Darné [42] analyze the weak form market efficiency of the same Euro exchanges rates as used by Belaire-Franch and Opong [41] and find that the given Euro exchange rates follow a random walk. Again, Belaire-Franch and Opong [43] analyze the same Euro exchange rates for the period 1999-2008 and the findings are in line with the findings of Charles and Darné [42].

Another set of studies use spectral tests to capture the weak form market efficiency of the foreign exchange rates. These include the studies by Fong and $\mathrm{Ou}$ liaris [44], Hong [45], Hong and Lee [46], Kuan and Lee [47], and Escanciano 
and Velasco [48]. Using spectral test as proposed by Durlauf [25], Fong and Ouliaris [44] analyze the same foreign exchange rates as used by Liu and He [37] and find the evidence of rejection of the efficient market hypothesis for the Great British pound. Hong [45] propose a generalized spectral test that is suitable for both linear and nonlinear time series analyses. Hong [45] observe rejection of the martingale difference hypothesis for the Deutschemark based on the proposed spectral test. Hong and Lee [46] apply the generalized spectral test on five major exchange rates as used by Wright [17] and find evidence of nonlinear dependence in these exchange rates. Kuan and Lee [47] propose a new spectral test based on the moment conditions derived by Bierens [5]. Kuan and Lee [47] apply the newly proposed spectral test on the same exchange rates as used by Hong and Lee [46] and obtain nearly similar findings as obtained by Hong and Lee [46] with the exception of Great British pound for which the null hypothesis of dependence in series is not rejected. Later, Escanciano and Velasco [48] and Escanciano and Lobato [49] use the generalized spectral test on the same exchange rates and obtain similar findings in confirmation with the findings of Hong and Lee [46].

Many studies in the literature have used the autocorrelation based tests to analyze the efficient market hypothesis (Hsieh [12]; Lobato et al. [50]; Horowitz et al. [51]; Escanciano and Lobato [49]; and Chortareas et al. [52]). Hsieh [12] analyze the statistical properties of the five major currencies (Great British pound, Japanese yen, Canadian dollar, Swiss franc and Deutschemark) for the period from 1974 to 1983 and reject the null of the efficient market hypothesis based on the results from the heteroscedasticity-adjusted Box-Pierce test. Lobato et al. [50] propose a modified Box-Pierce test applied it to analyze the dependence structure in the daily returns of the Great British pound, Japanese yen, Swiss franc and Deutschemark and do not observe the rejection of the efficient market hypothesis for all the given currencies. Using bootstrapped Box-Pierce test, Horowitz et al. [51] find no evidence of linear dependence in returns of the Great British pound. Moreover, Escanciano and Lobato [49] do not find any evidence of linear dependence in the Great British pound, Japanese yen and Canadian dollar. Using the generalized Andrews-Ploberger autocorrelation tests, Chortareas et al. [52] analyze the efficient market hypothesis of various OECD exchange rates. The findings indicate that the efficient market hypothesis is not rejected for most of the OECD exchange rates.

Most of these studies analyze the efficient market hypothesis and do not discuss the implications of the adaptive market hypothesis. In this study, we test the martingale hypothesis on the Indian exchange rates relative to the US dollar, Euro, GBP and Japanese yen and discuss the implication of the adaptive market hypothesis based on non-overlapping and overlapping moving window analysis.

\section{Methodology}

\subsection{Martingale Hypothesis}

In the martingale model, the next period price is expected to be the same as the 
current price. Suppose $x_{t+1}$ represents the next period exchange rate and for $x_{t+1}$ to follow a martingale process:

$$
E_{t+1}\left(x_{t+1} / \Omega_{t}\right)=x_{t}
$$

where $\Omega_{t}$ is the information set with up to time $\mathrm{t}$ and it also includes $x_{t}$. The martingale process also implies that $x_{t+1}-X_{t}$ is a fair game, that is,

$$
E_{t+1}\left(\left(x_{t+1}-x_{t}\right) / \Omega_{t}\right)=0
$$

\subsection{Automatic Variance Ratio Test}

Suppose $P_{t}$ is an asset price at time $t$, where $t=1, \cdots, T$, and $x_{t}$ be $\ln \left(P_{t}\right)$ as the natural $\log$ of the price series. Hence the first order autoregressive model is given as:

$$
y_{t}=\mu+\varnothing y_{t-1}+\varepsilon_{t}
$$

where $\mu$ is an arbitrary drift parameter and $\varepsilon_{t}$ is the random disturbance term. The random walk hypothesis (RWH) corresponds to $\varnothing=1$ in Equation (1) and implies that the variance of the log price increments is linear in the observation interval, as shown by Lo-MacKinlay [16]. It plays a very important role in testing weak form market efficiency. The variance ratio test exploits the property that, if a series of asset return is purely random, then the variance of $k$-period return ( $k$-period differences of $y_{t}$ ) is $k$ times the variance of one-period return. Choi [18] proposes variance ratio test based on the frequency domain which uses a data-dependent procedure to estimate the optimal value of $k$. Choi [18] also employs the Quadratic Spectral kernel to estimate variance ratio. The Choi's variance ratio estimator is defined as

$$
V R(k)=1+2 \sum_{i=1}^{T-1} m(i / k) \hat{\rho}(i)
$$

where

$$
\hat{\rho}(i)=\frac{\sum_{t=1}^{T}\left(y_{t}-\hat{\mu}\right)\left(y_{t+i}-\hat{\mu}\right)}{\sum_{t=1}^{T}\left(y_{t}-\hat{\mu}\right)^{2}}
$$

and

$$
\hat{\mu}=\frac{1}{T} \sum_{i=1}^{T-1} y_{t} \text { and } y_{t}=x_{t}-x_{t-1}
$$

and

$$
m(r)=\frac{25}{12 \pi^{2} r^{2}}\left[\frac{\sin \left(\frac{6 \pi r}{5}\right)}{\frac{6 \pi r}{5}}-\cos \left(\frac{6 \pi r}{5}\right)\right]
$$

where $m(r)$ is the quadratic spectral kernel. Choi [18] has stated that $V R(k)$ is a consistent estimator of $2 \pi f_{y}(0)$, where $f_{x}($.$) denotes the normalized spectral den-$ sity of the time series $\left\{X_{t}\right\}$. Choi [18] has also stated that under the null hypothesis $\left(\mathrm{H}_{0}: 2 \pi f_{y}(0)=1\right)$ the $A V R(k)$ statistic defined as 


$$
A V R(k)=\frac{\sqrt{\frac{T}{k}}[V R(k)-1]}{\sqrt{2}} \stackrel{d}{\longrightarrow} N(0,1)
$$

as $k \rightarrow \infty, T \rightarrow \infty, T / k \rightarrow \infty$. This variance ratio test is a two-sided test, and its critical values are taken from both the tails of the standard normal distribution. The $A V R(k)$ result holds when $y_{t}$ is IID with a finite fourth moment.

\subsection{Belaire-Franch and Contreras Tests [21]}

Using signs and ranks, Wright [17] provides the non-parametric variance ratio tests to test the martingale hypothesis. Wright [17] finds that rank-based tests show low size distortion, under conditional heteroscedasticity. Suppose $\left\{y_{1}, \cdots, y_{T}\right\}$ be the return series, then ranks $R_{1}$ and $R_{2}$ are defined as:

$$
R_{1}(k)=\left(\frac{\frac{1}{T k} \sum_{t=k+1}^{T}\left(r_{1 t}+r_{1 t-1}+\cdots+r_{1 t-k}\right)^{2}}{\frac{1}{T} \sum_{t=1}^{T} r_{1 t}^{2}}-1\right) \times\left(\frac{2(2 k-1)(k-1)}{3 k T}\right)^{-1 / 2}
$$

and

$$
R_{2}(k)=\left(\frac{\frac{1}{T k} \sum_{t=k+1}^{T}\left(r_{2 t}+r_{2 t-1}+\cdots+r_{2 t-k}\right)^{2}}{\frac{1}{T} \sum_{t=1}^{T} r_{2 t}^{2}}-1\right) \times\left(\frac{2(2 k-1)(k-1)}{3 k T}\right)^{-1 / 2}
$$

where

$$
\begin{gathered}
r_{1 t}=\left(r\left(y_{t}\right)-\frac{T+1}{2}\right) \div \sqrt{\frac{(T-1)(T+1)}{12}} \\
r_{2 t}=\Phi^{-1}\left(r\left(y_{t}\right) /(T+1)\right)
\end{gathered}
$$

The tests based on signs of martingale sequence are given as

$$
\begin{gathered}
S_{1}(k)=\left(\frac{\frac{1}{T k} \sum_{t=k+1}^{T}\left(s_{t}+s_{t-1}+\cdots+s_{t-k}\right)^{2}}{\frac{1}{T} \sum_{t=1}^{T} s_{t}^{2}}-1\right) \times\left(\frac{2(2 k-1)(k-1)}{3 k T}\right)^{-1 / 2} \\
S_{2}(k)=\left(\frac{\frac{1}{T k} \sum_{t=k+1}^{T}\left(s_{t}(\bar{\mu})+s_{t-1}(\bar{\mu})+\cdots+s_{t-k}(\bar{\mu})\right)^{2}}{\frac{1}{T} \sum_{t=1}^{T} s_{t}^{2}(\bar{\mu})}-1\right) \times\left(\frac{2(2 k-1)(k-1)}{3 k T}\right)^{-1 / 2}
\end{gathered}
$$

Belaire-Franch and Contreras [21] substitute the standard variance ratio tests by Wright's ranks and signs-based tests. The statistics are defined as:

$$
\begin{aligned}
& C D_{\left(R_{1}\right)}=\max _{1 \leq i \leq m}\left|R_{1}\left(k_{i}\right)\right| \\
& C D_{\left(R_{2}\right)}=\max _{1 \leq i \leq m}\left|R_{2}\left(k_{i}\right)\right| \\
& C D_{\left(S_{1}\right)}=\max _{1 \leq i \leq m}\left|S_{1}\left(k_{i}\right)\right| \\
& C D_{\left(S_{2}\right)}=\max _{1 \leq i \leq m}\left|S_{2}\left(k_{i}\right)\right|
\end{aligned}
$$


The rank-based procedures are exact under the i.i.d. assumption whereas the signs-based procedures are exact under both the i.i.d. and martingale difference sequence assumptions. Belaire-Franch and Contreras [21] showed that the rank-based tests $C D_{\left(R_{1}\right)}$ and $C D_{\left(R_{2}\right)}$ are more powerful than their signs-based counterparts. In this paper, we only report the results based on the rank-based tests.

\section{Data and Preliminary Analysis}

\subsection{Dataset}

We use daily closing levels of the Indian exchange rates relative to US dollar, Great British Pound, Euro and Japanese yen. All the data have been obtained from the Bloomberg database. The period of study is from January 1999 to November 2017.

\subsection{Descriptive Statistics}

Table 1 provides the descriptive statistics of the Indian nominal exchange rate returns under study. The average return is positive for all the exchange rates except for the case of Japanese yen. Moreover, the Japanese yen exchange rate seems to be highly volatile and the US dollar exchange rate is the least volatile. The Jarque-Bera statistic confirms the significant non-normality in the exchange rates except for the Euro. The ARCH-LM test supports the presence of conditional heteroskedasticity in the return series. The Ljung Box statistic up to 20 lags supports the evidence of a violation of the random walk hypothesis for the USD and Japanese yen.

\section{Empirical Results}

We first start with the whole sample analysis to validate the martingale hypothesis in the nominal Indian exchange rates relative to the US dollar, GBP, Euro and Japanese yen. Next, we examine the evolution of the efficiency characteristics of the Indian exchange rates using annual non-overlapping moving window approach. Finally, we examine the evolution of efficiency characteristics of the Indian exchange rates using overlapping moving window approach. The moving window approach also helps us to examine the validity of the Adaptive Market Hypothesis (AMH) in which the degree of market efficiency varies with time depending on the market conditions.

\subsection{Whole Sample Analysis}

Table 2 reports the whole sample results of automatic variance ratio (AVR) test and rank based Belaire-Franch and Contreras [21] tests. To compute the automatic variance ratio test statistics, we utilize the BIC (maximum lag for BIC is set to 20) selection criteria to choose an approximating AR model as explained in the Methodology section. We then estimate an optimal truncation point using Andrews [36] methodology to compute the automatic variance ratio test statistic. 
Table 1. Descriptive statistics.

\begin{tabular}{ccccc}
\hline & USD & GBP & Euro & Yen \\
\hline Mean & 0.009 & 0.004 & 0.009 & -0.009 \\
Median & 0.000 & 0.013 & 0.009 & 0.004 \\
Min & -3.294 & -7.243 & -3.854 & -4.965 \\
Max & 3.904 & 4.806 & 3.938 & 5.141 \\
Stdev & 0.388 & 0.623 & 0.650 & 0.797 \\
Skewness & 0.257 & -0.453 & 0.026 & -0.199 \\
Kurtosis & 12.844 & 10.120 & 5.286 & 7.166 \\
JB test & $19157.191^{\#}$ & $10156.462^{\#}$ & $1031.329^{\#}$ & $3452.672^{\#}$ \\
Q(20) & $84.660^{\#}$ & 22.682 & 27.611 & $39.663^{\#}$ \\
ARCH(10) & $1068.159^{\#}$ & $398.665^{\#}$ & $335.395^{\#}$ & $408.701^{\#}$ \\
\hline
\end{tabular}

\# means significant at $1 \%$ level of significance. Note that Stdev represents the standard deviation, JB stat represents the Jarque Bera statistic, Q(20) indicates the Ljung-Box Q statistic up to 20 lags and ARCH(10) indicates the Lagrange multiplier test for conditional heteroskedasticity up to 10 lags.

Table 2. Automatic variance ratio test and Belaire-Franch and Contreras rank-based tests: Whole sample analysis.

\begin{tabular}{ccccc}
\hline & USD/INR & GBP/INR & Euro/INR & INR/JPY \\
\hline AVR statistic & 0.607 & -0.147 & -0.011 & $-1.803^{\dagger}$ \\
AVR p-value & 0.590 & 0.830 & 0.967 & 0.083 \\
$\quad C D_{\left(R_{1}\right)} \quad$ statistic & $3.069^{*}$ & 1.424 & 1.094 & $2.755^{\star}$ \\
$C D_{\left(R_{1}\right)} \quad$ Critical Value (5\%) & 2.195 & 2.195 & 2.195 & 2.195 \\
$\quad C D_{\left(R_{2}\right)}$ statistic & $3.516^{*}$ & 1.200 & 0.868 & $2.772^{*}$ \\
$C D_{\left(R_{2}\right)}$ Critical Value (5\%) & 2.292 & 2.292 & 2.292 & 2.292 \\
\hline
\end{tabular}

${ }^{*}$ and $\dagger$ mean significant at $5 \%$ and $1 \%$ levels of significance, respectively.

The results based on the AVR test indicate that the null of the no serial correlation is rejected at the $10 \%$ level of significance only for the Indian exchange rate relative to Japanese yen. For the rest of the exchange rates, the null hypothesis of the no serial correlation is not violated based on the AVR test al conventional levels of significance. However, based on the Belaire-Franch and Contreras [21] rank-based tests (both $C D_{\left(R_{1}\right)}$ and $\left.C D_{\left(R_{2}\right)}\right)$, the Indian exchange rates relative to the US dollar and Japanese yen exhibit characteristics of inefficiency at 5\% level of significance. Overall, the results based on the whole sample analysis provide weak evidence of market inefficiency in the Indian exchange rates relative to the US dollar and Japanese yen. We do not find any evidence of violation of the martingale hypothesis in the Indian exchange rates relative to GBP and Euro.

\subsection{Non-Overlapping Moving Window Analysis}

Figure 1(a) to Figure 1(c) report the results of non-overlapping moving window analysis based on the AVR test and Belaire-Franch and Contreras [21] rank-based 
tests. We plot p-values for the AVR test. However, we plot $C D_{\left(R_{1}\right)}$ and $C D_{\left(R_{2}\right)}$ statistic for the Belaire-Franch and Contreras [21] rank based tests. For the AVR test, when the p-values are less than $10 \%$ and $5 \%$, the martingale hypothesis is rejected at $10 \%$ and $5 \%$ levels of significance respectively. The critical value for the $C D_{\left(R_{1}\right)}$ are 1.943 and 2.259 at $10 \%$ and $5 \%$ levels of significance respectively. The critical value for the $C D_{\left(R_{2}\right)}$ are 1.968 and 2.239 at $10 \%$ and $5 \%$ levels of significance respectively. When the $C D_{\left(R_{1}\right)}$ and $C D_{\left(R_{2}\right)}$ statistics exceed the respective critical values, the martingale hypothesis is rejected at that level of significance. The results clearly indicate that the market efficiency in the Indian exchange rates does not remain constant and exhibit dynamic behavior. The US dollar exhibits violation of the martingale hypothesis in year 2000 based on all three tests. We also observe the presence of market inefficiency in the US dollar in 2005 based on both Belaire-Franch and Contreras [21] rank based tests. In

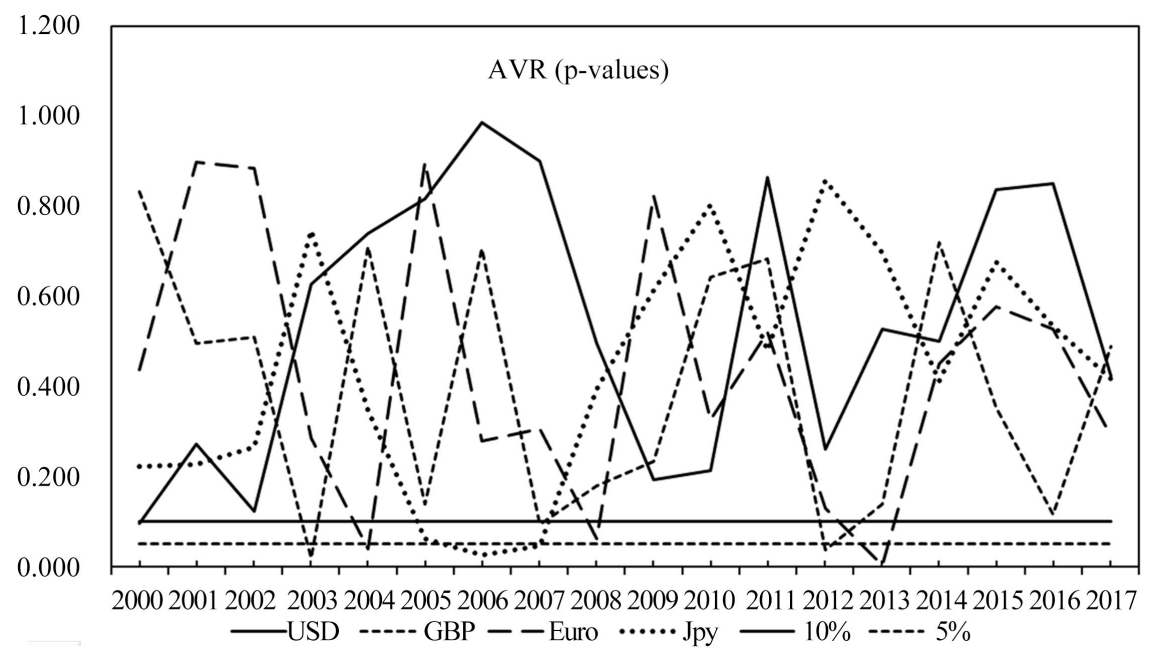

(a)

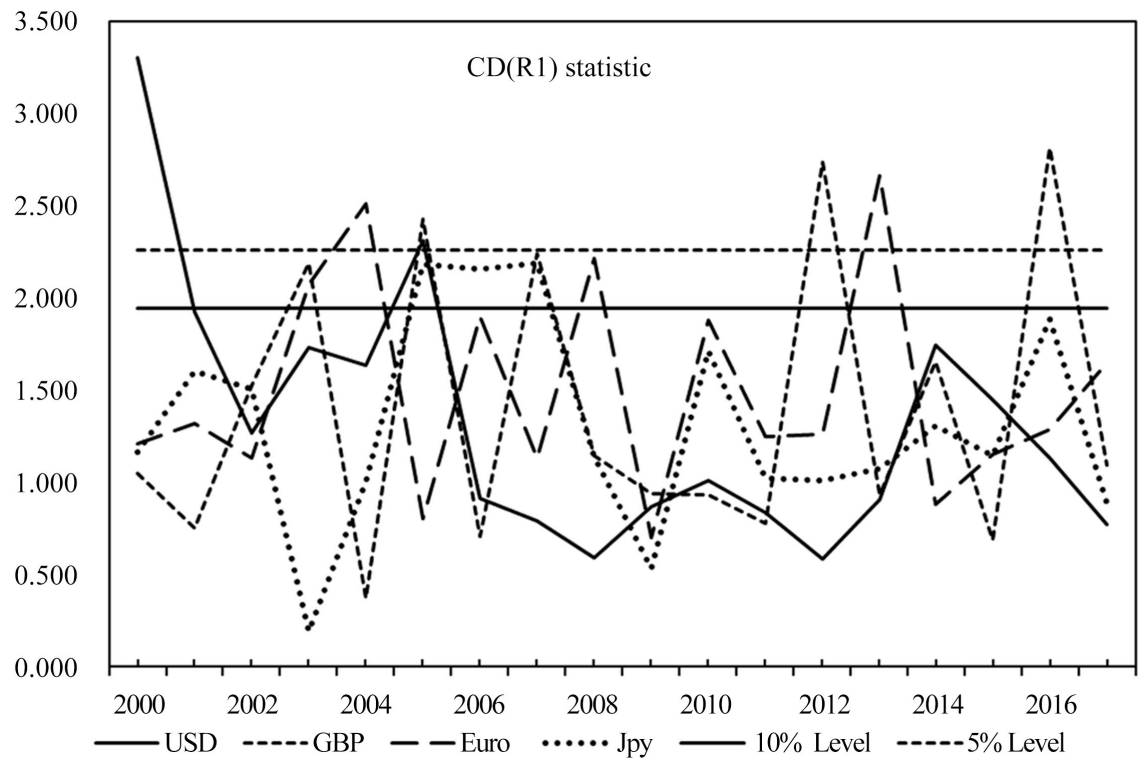

(b) 


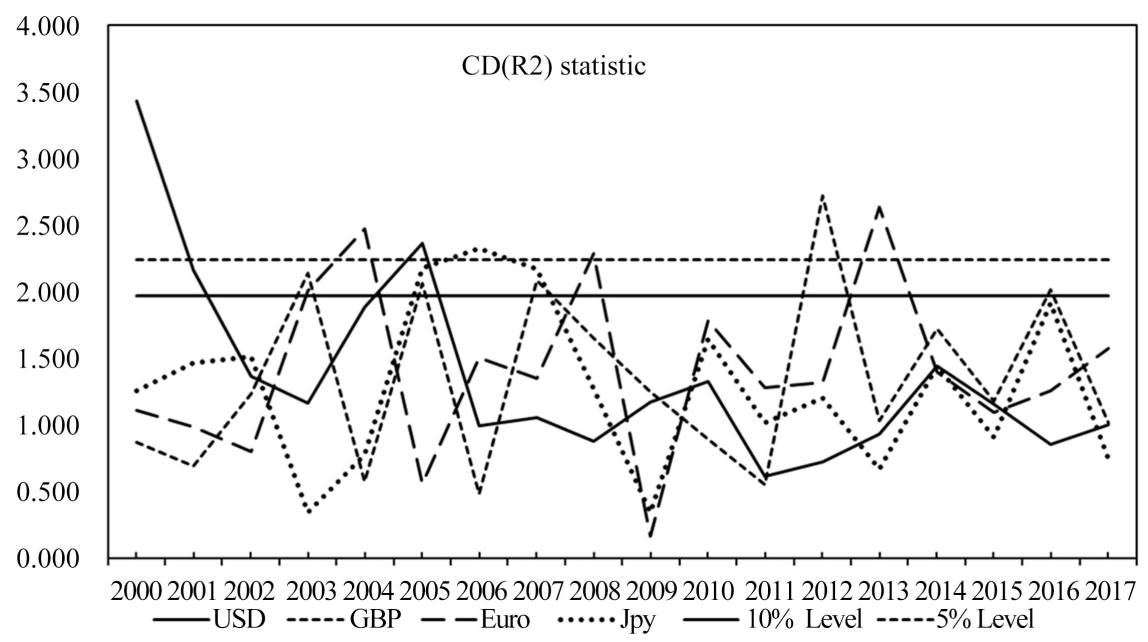

(c)

Figure 1. (a) Time-varying p-values based on AVR test (non-overlapping window analysis): The moving window size is equal to the number of days in the given year. The p-value less than $10 \%$ and $5 \%$ represent the rejection of martingale hypothesis at $10 \%$ and $5 \%$ levels of significance respectively; (b) Time-varying $C D_{\left(R_{1}\right)}$ statistic (non-overlapping window analysis): The moving window size is equal to the number of days in the given year. If the value of the $C D_{\left(R_{1}\right)}$ statistic is greater than 1.943 and 2.259, then the $C D_{\left(R_{1}\right)}$ statistic is statistically significant at $10 \%$ and $5 \%$ levels of significance respectively; (c) Time-varying $C D_{\left(R_{2}\right)}$ statistic (non-overlapping window analysis): The moving window size is equal to the number of days in the given year. If the value of the $C D_{\left(R_{1}\right)}$ statistic is greater than 1.968 and 2.239 , then the $C D_{\left(R_{2}\right)}$ statistic is statistically significant at $10 \%$ and $5 \%$ levels of significance respectively.

case of GBP, we find evidence of violation of the martingale hypothesis in years 2003, 2007 and 2012 based on all the three tests under study. In addition to this, the Belaire-Franch and Contreras [21] rank based tests provide evidence of inefficiency in GBP in years 2005 and 2016. This indicates that even though GBP is informationally efficient in the whole sample, its efficiency characteristics vary dynamically over the study period which supports the validity of the adaptive market hypothesis. For Euro, the martingale hypothesis is rejected in years 2004, 2008 and 2014 based on all the three tests. The Belaire-Franch and Contreras [21] rank based tests also provide evidence of rejection of martingale hypothesis in 2003 for Euro. For the Japanese yen, all three tests exhibit violation of martingale hypothesis in years 2005, 2006 and 2007. Overall, the evolution of market efficiency across all Indian exchange rates is clearly visible based on the non-overlapping rolling window analysis. The rejection of the martingale hypothesis during 2003-2005 in the Indian exchange rates can be related to increase in domestic inflation and increase in commodity prices. Moreover, we observe violation of martingale hypothesis for nearly all exchange rates except for GBP during the period of sub-prime crisis. We also observe the evidence of return predictability in Indian exchange rate relative to Euro during the European sovereign debt crisis. 


\subsection{Overlapping Moving Window Analysis}

Figure 2(a) to Figure 2(c) report the results of the overlapping moving window analysis based on the AVR test and Belaire-Franch and Contreras [21] rank-based tests for all the exchange rates under study. The size of the rolling window is taken as 1000 which is equivalent to approximately 4 years of daily data. The selected window size is large enough to take care of any deficiencies



20022004200620082010201220142016

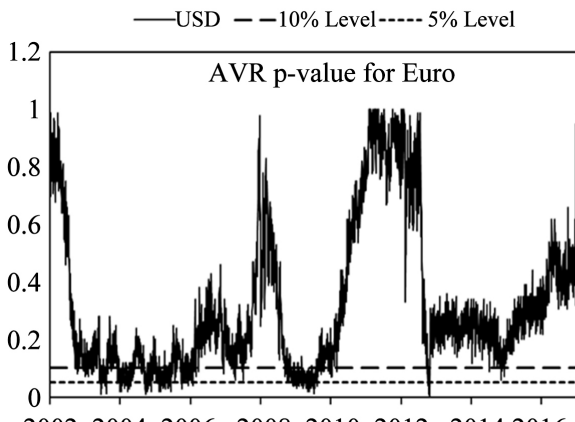

20022004200620082010201220142016

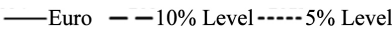

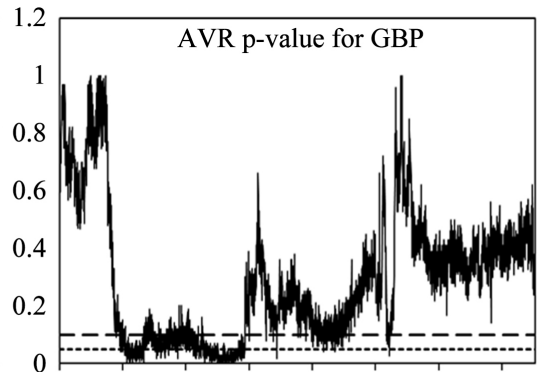

20022004200620082010201220142016

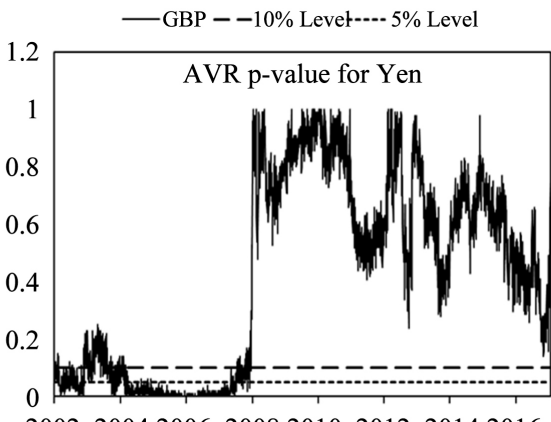

20022004200620082010201220142016 - Yen $--10 \%$ Level-----5\% Level

(a)
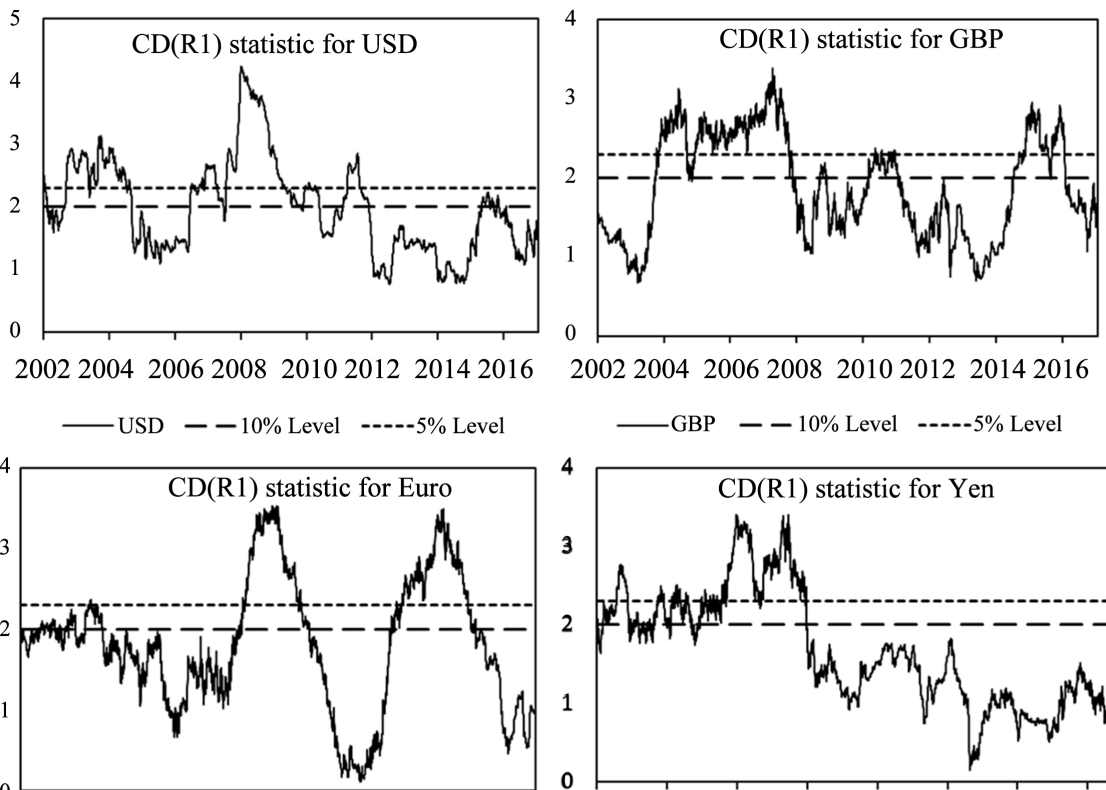

20022004200620082010201220142016

- Euro - - $10 \%$ Level ------5\% Level

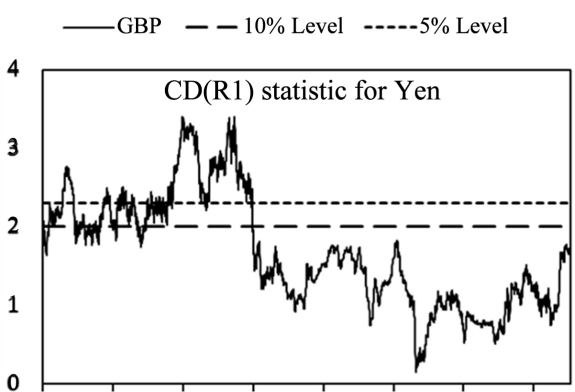

20022004200620082010201220142016

- Yen $\quad-\quad 10 \%$ Level $\quad---\cdot-5 \%$ Level

(b) 


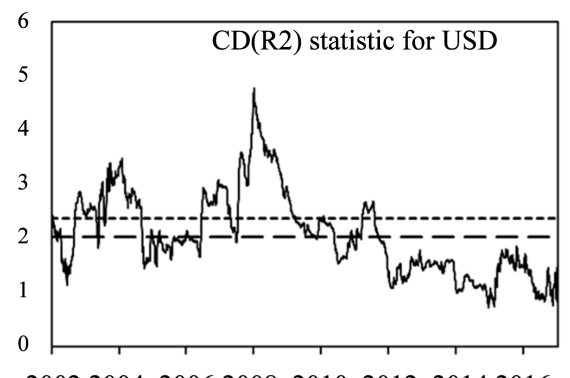

20022004200620082010201220142016

— USD - - $10 \%$ Level -----.5\% Level

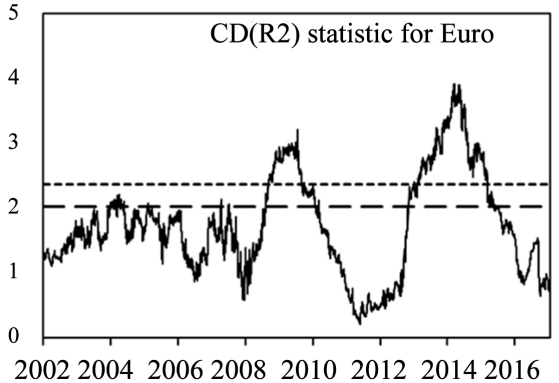

20022004200620082010201220142016

_ Euro - - $10 \%$ Level -.... $5 \%$ Level

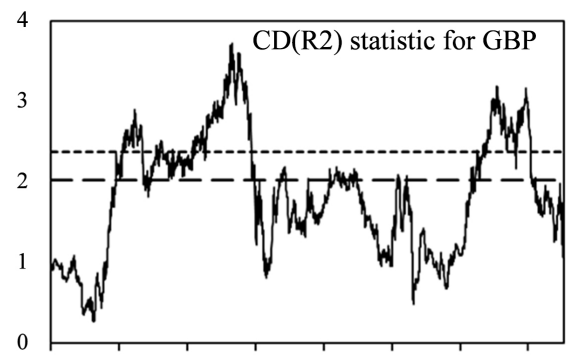

20022004200620082010201220142016
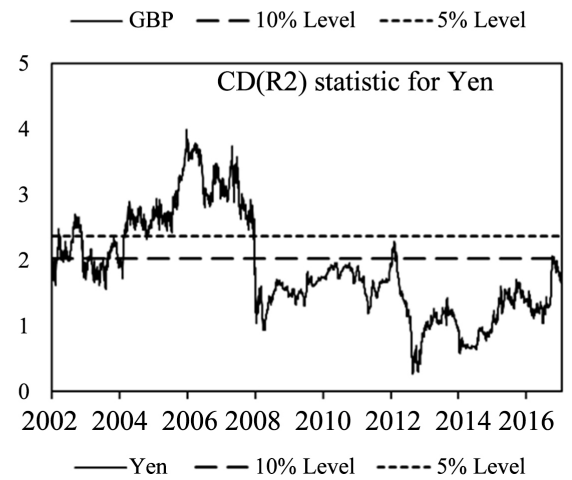

(c)

Figure 2. (a) Time-varying p-values based on AVR test (overlapping window analysis): The size of the rolling window is taken as 1000 which is equivalent to approximately 4 years of daily data. The p-value less than $10 \%$ and $5 \%$ represent the rejection of martingale hypothesis at $10 \%$ and $5 \%$ levels of significance respectively; (b) Time-varying $C D_{\left(R_{1}\right)}$ statistic (overlapping window analysis): The size of the rolling window is taken as 1000 which is equivalent to approximately 4 years of daily data. If the value of the $C D_{\left(R_{1}\right)}$ statistic is greater than 2.0017 and 2.2951 , then the $C D_{\left(R_{1}\right)}$ statistic is statistically significant at $10 \%$ and $5 \%$ levels of significance respectively; (c) Time-varying $C D_{\left(R_{2}\right)}$ statistic (overlapping window analysis): The size of the rolling window is taken as 1000 which is equivalent to approximately 4 years of daily data. If the value of the $C D_{\left(R_{1}\right)}$ statistic is greater than 2.0229 and 2.3691 , then the $C D_{\left(R_{2}\right)}$ statistic is statistically significant at $10 \%$ and $5 \%$ levels of significance respectively.

due to possible small sample size for the tests under study. We plot p-values for the AVR test. However, we plot $C D_{\left(R_{1}\right)}$ and $C D_{\left(R_{2}\right)}$ statistic for the Belaire-Franch and Contreras [21] rank based tests. For the AVR test, when the p-values are less than $10 \%$ and $5 \%$, the martingale hypothesis is rejected at $10 \%$ and $5 \%$ levels of significance respectively. The critical value for the $C D_{\left(R_{1}\right)}$ are 2.0017 and 2.2951 at $10 \%$ and $5 \%$ levels of significance respectively. The critical value for the $C D_{\left(R_{2}\right)}$ are 2.0229 and 2.3691 at $10 \%$ and $5 \%$ levels of significance respectively. When the $C D_{\left(R_{1}\right)}$ and $C D_{\left(R_{2}\right)}$ statistics exceed the respective critical values, the martingale hypothesis is rejected at that level of significance. Through this, we can identify the periods when the return predictability is statistically significant in Indian exchange rates and can relate them with various macroeconomic, financial and political events. 
The US dollar displays a departure from the martingale hypothesis for some period of 2004, during the sub-prime crisis (2008-09) and during the European sovereign debt crisis (2011) based on the AVR test and Belaire-Franch and Contreras [21] rank-based tests. Based on the Belaire-Franch and Contreras [21] rank-based tests, we also observe a violation of martingale hypothesis during 2003 and 2006.

We find evidence of return predictability in GBP during 2004-2008, 2010-11 and for some period in 2012 based on the AVR test and Belaire-Franch and Contreras [21] rank-based tests. However, we also observe the violation of martingale hypothesis in GBP during 2015-16 based on the Belaire-Franch and Contreras [21] rank-based tests.

For Euro, we observe the rejection of the martingale hypothesis during 2003-2008, for some periods in 2009-10, 2013 and 2015 based on the AVR test. However, based on the Belaire-Franch and Contreras [21] rank-based tests, we observe rejection of martingale hypothesis during 2003-04, 2008-10 and 2013-15.

For Japanese yen, the null hypothesis of no return predictability is rejected for a period from 2002 to 2008 based on the AVR test and Belaire-Franch and Contreras [21] rank-based tests. We also observe rejection of the martingale hypothesis based on the 10\% level of significance during 2012 and 2017 based on the $C D_{\left(R_{2}\right)}$ test statistic.

The violation of the martingale hypothesis during 2002-2004 can be related to the increase in commodity prices and domestic inflation. The evidence of return predictability around 2008 can be related to the turbulence in the market due to the impact of the global financial crisis. This change in behavioral characteristics of the Indian exchange rates during the global financial crisis can be attributed to the central bank and government intervention. Moreover, the rejection of martingale hypothesis during 2012-2016 can be attributed to the impact of European sovereign debt crisis and decline in the crude oil prices. Overall, the findings indicate that all the Indian exchange rates exhibit deviation from the martingale behavior in a number of periods which can be related to various macroeconomic events. This indicates that the Indian exchange rates exhibit time-varying efficiency characteristics and exhibit inefficient behavior during the periods of major macroeconomic events. These time-varying non-martingale periods which indicate the periods of predictability of returns are consistent with the validity and implication of the Adaptive Market Hypothesis in the Indian exchange rates.

\subsection{Policy Implication}

This analysis is important because inefficiency in market behavior leads traders, fund managers and portfolio managers to develop profitable trading strategies to take out an extraordinary gain. Moreover, the efficiency characteristics of a market influence its regulatory framework and market development. The time-varying efficiency characteristics of the market can help the regulators and 
policymakers to incorporate financial innovations and economic development based on the changing efficiency of the market.

\section{Conclusion}

The study examines the evolution of market efficiency in Indian exchange rates relative to the US dollar, GBP, Euro and Japanese yen using daily data. We use the automatic variance ratio test and Belaire-Franch and Contreras [21] rank-based tests to achieve the goals. We also evaluate the return predictability in the Indian exchange rates based on whole sample analysis. Our findings provide evidence in support of violation of the martingale hypothesis of Indian exchange rates relative to the US dollar and Japanese yen for the whole sample period. We use overlapping and non-overlapping moving subsample approach to examine the evolution of market efficiency and to test the validity of the adaptive market hypothesis in the Indian exchange rates. This also helps us to analyze the sensitivity of results to a particular sample period. Our findings based on moving sub-sample approach highlight the unpredictable behavior of the Indian exchange rates for most of the times, however, around major macroeconomic events, we observe episodes of the inefficient behavior of the Indian exchange rates. This can be related to the fact that during the periods of crashes and crisis, the economy is under the impact of liquidity crisis, financial panic and chaotic market conditions, which may lead to expected non-linear dynamics in markets and hence results in episodes of inefficiency. This suggests that the efficiency characteristics of returns in Indian exchange rates do not remain constant and are influenced by changing market conditions, which is consistent with the validity of the adaptive market hypothesis. This also indicates that based on the changing market conditions, the trader can design and implement appropriate trading strategies to take out extra-ordinary gain. The findings also indicate that the profitable opportunities through trading in the Indian exchange rate market are episodic in nature. The current study lacks the implementation of the economic significance of the inefficient behavior of the Indian exchange rates. Further research can be conducted to explore the economic significance of inefficient behavior of the Indian exchange rates.

\section{References}

[1] Bachelier, L. (1900) Theorie de la speculation. Annales Scientifiques de PÉcole Normale Supérieure, 17, 21-86. https://doi.org/10.24033/asens.476

[2] Cootner, P.H. (1964) The Random Character of Stock Market Prices. MIT Press, Cambridge, MA.

[3] Samuelson, P.A. (1965) Proof that Properly Anticipated Prices Fluctuate Randomly. Industrial Management Review, 6, 41-49.

[4] Fama, E.F. (1970) Efficient Capital Markets: A Review of Theory and Empirical Work. The Journal of Finance, 25, 383-417. https://doi.org/10.2307/2325486

[5] Bierens, H.J. (1982) Consistent Model Specification Tests. Journal of Econometrics, 20, 105-134. https://doi.org/10.1016/0304-4076(82)90105-1 
[6] Smith, G., Jefferis, K. and Ryoo, H.J. (2002) African Stock Markets: Multiple Variance Ratio Tests of Random Walks. Applied Financial Economics, 12, 475-484. https://doi.org/10.1080/09603100010009957

[7] Giddy, I.H. and Dufey, G. (1975) The Random Behavior of Flexible Exchange Rates: Implications for Forecasting. Journal of International Business Studies, 6, 1-32. https://doi.org/10.1057/palgrave.jibs.8490765

[8] Roll, R. (1979) Violations of Purchasing Power Parity and Their Implications for Efficient International Commodity Markets. International Finance and Trade, 1, 133-176.

[9] Meese, R.A. and Singleton, K.J. (1982) On Unit Roots and the Empirical Modeling of Exchange Rates. The Journal of Finance, 37, 1029-1035. https://doi.org/10.1111/j.1540-6261.1982.tb03595.x

[10] Adler, M. and Lehmann, B. (1983) Deviations from Purchasing Power Parity in the Long Run. The Journal of Finance, 38, 1471-1487. https://doi.org/10.1111/j.1540-6261.1983.tb03835.x

[11] Darby, M.R. (1983) Movements in Purchasing Power Parity: The Short and Long Runs. In: The International Transmission of Inflation, University of Chicago Press, Chicago, 462-477.

[12] Hsieh, D.A. (1988) The Statistical Properties of Daily Foreign Exchange Rates: 1974-1983. Journal of International Economics, 24, 129-145. https://doi.org/10.1016/0022-1996(88)90025-6

[13] Baillie, R.T. and Bollerslev, T. (1989) Common Stochastic Trends in a System of Exchange Rates. The Journal of Finance, 44, 167-181. https://doi.org/10.1111/j.1540-6261.1989.tb02410.x

[14] Huizinga, J. (1987) An Empirical Investigation of the Long-Run Behavior of Real Exchange Rates. Carnegie-Rochester Conference Series on Public Policy, 27, 149-214.

[15] Grilli, V. and Kaminsky, G. (1991) Nominal Exchange Rate Regimes and the Real Exchange Rate: Evidence from the United States and Great Britain, 1885-1986. Journal of Monetary Economics, 27, 191-212. https://doi.org/10.1016/0304-3932(91)90041-L

[16] Lo, A.W. and MacKinlay, A.C. (1988) Stock Market Prices Do Not Follow Random Walks: Evidence from a Simple Specification Test. The Review of Financial Studies, 1, 41-66. https://doi.org/10.1093/rfs/1.1.41

[17] Wright, J.H. (2000) Alternative Variance-Ratio Tests Using Ranks and Signs. Journal of Business \& Economic Statistics, 18, 1-9.

[18] Choi, I. (1999) Testing the Random Walk Hypothesis for Real Exchange Rates. Journal of Applied Econometrics, 14, 293-308. https://doi.org/10.1002/(SICI)1099-1255(199905/06)14:3<293::AID-JAE503>3.0.CO $\underline{; 2-5}$

[19] Chow, K.V. and Denning, K.C. (1993) A Simple Multiple Variance Ratio Test. Journal of Econometrics, 58, 385-401. https://doi.org/10.1016/0304-4076(93)90051-6

[20] Whang, Y.J. and Kim, J. (2003) A Multiple Variance Ratio Test Using Subsampling. Economics Letters, 79, 225-230. https://doi.org/10.1016/S0165-1765(02)00330-0

[21] Belaire-Franch, J. and Contreras, D. (2004) Ranks and Signs-Based Multiple Variance Ratio Tests. Spanish-Italian Meeting on Financial Mathematics, Cuenca, November 2003, Vol. 7, 40-79. 
[22] Chen, W.W. and Deo, R.S. (2006) The Variance Ratio Statistic at Large Horizons. Econometric Theory, 22, 206-234. https://doi.org/10.1017/S0266466606060099

[23] Box, G.E. and Pierce, D.A. (1970) Distribution of Residual Autocorrelations in Autoregressive-Integrated Moving Average Time Series Models. Journal of the American statistical Association, 65, 1509-1526. https://doi.org/10.1080/01621459.1970.10481180

[24] Ljung, G.M. and Box, G.E. (1978) On a Measure of Lack of Fit in Time Series Models. Biometrika, 65, 297-303. https://doi.org/10.1093/biomet/65.2.297

[25] Durlauf, S.N. (1991) Spectral Based Testing of the Martingale Hypothesis. Journal of Econometrics, 50, 355-376. https://doi.org/10.1016/0304-4076(91)90025-9

[26] Hong, Y. (1996) Consistent Testing for Serial Correlation of Unknown Form. Econometrica: Journal of the Econometric Society, 64, 837-864. https://doi.org/10.2307/2171847

[27] Kumar, D. and Maheswaran, S. (2012) Testing the Martingale Hypothesis in the Indian Stock Market: Evidence from Multiple Variance Ratio Tests. Decision, 39, $62-85$.

[28] Kumar, D. (2013) Are PIIGS Stock Markets Efficient? Studies in Economics and Finance, 30, 209-225. https://doi.org/10.1108/SEF-09-2011-0074

[29] Kumar, D. and Maheswaran, S. (2014) Are Major Global Stock Markets Efficient? An Application of the Martingale Difference Hypothesis with Wild Bootstrap. American Journal of Finance and Accounting, 3, 217-233. https://doi.org/10.1504/AJFA.2014.060818

[30] Lo, A.W. (2004) The Adaptive Markets Hypothesis: Market Efficiency from an Evolutionary Perspective. Journal of Portfolio Management, 30, 15-29.

[31] Lo, A.W. (2005) Reconciling Efficient Markets with Behavioral Finance: The Adaptive Markets Hypothesis. Journal of Investment Consulting, 7, 21-44.

[32] Ito, M., Noda, A. and Wada, T. (2014) International Stock Market Efficiency: A Non-Bayesian Time-Varying Model Approach. Applied Economics, 46, 2744-2754. https://doi.org/10.1080/00036846.2014.909579

[33] Ito, M., Noda, A. and Wada, T. (2016) The Evolution of Stock Market Efficiency in the US: A Non-Bayesian Time-Varying Model Approach. Applied Economics, 48, 621-635. https://doi.org/10.1080/00036846.2015.1083532

[34] Kim, J.H., Shamsuddin, A. and Lim, K.P. (2011) Stock Return Predictability and the Adaptive Markets Hypothesis: Evidence from Century-Long US Data. Journal of Empirical Finance, 18, 868-879. https://doi.org/10.1016/j.jempfin.2011.08.002

[35] Lim, K.P., Luo, W. and Kim, J.H. (2013) Are US Stock Index Returns Predictable? Evidence from Automatic Autocorrelation-Based Tests. Applied Economics, 45, 953-962. https://doi.org/10.1080/00036846.2011.613782

[36] Andrews, D.W. (1991) Heteroskedasticity and Autocorrelation Consistent Covariance Matrix Estimation. Econometrica: Journal of the Econometric Society, 59, 817-858. https://doi.org/10.2307/2938229

[37] Liu, C.Y. and He, J. (1991) A Variance-Ratio Test of Random Walks in Foreign Exchange Rates. The Journal of Finance, 46, 773-785.

https://doi.org/10.1111/j.1540-6261.1991.tb02686.x

[38] Fong, W.M., Koh, S.K. and Ouliaris, S. (1997) Joint Variance-Ratio Tests of the Martingale Hypothesis for Exchange Rates. Journal of Business \& Economic Statistics, 15, 51-59.

[39] Yilmaz, K. (2003) Martingale Property of Exchange Rates and Central Bank Inter- 
ventions. Journal of Business \& Economic Statistics, 21, 383-395.

https://doi.org/10.1198/073500103288619034

[40] Chang, Y. (2004) A Re-Examination of Variance-Ratio Test of Random Walks in Foreign Exchange Rates. Applied Financial Economics, 14, 671-679.

https://doi.org/10.1080/0960310042000233449

[41] Belaire-Franch, J. and Opong, K.K. (2005) Some Evidence of Random Walk Behavior of Euro Exchange Rates Using Ranks and Signs. Journal of Banking \& Finance, 29, 1631-1643. https://doi.org/10.1016/j.jbankfin.2004.06.031

[42] Charles, A. and Darné, O. (2009) Testing for Random Walk Behavior in Euro Exchange Rates. Économie internationale, No. 3, 25-45.

[43] Belaire-Franch, J. and Opong, K.K. (2010) Testing for Random Walk in Euro Exchange Rates Using the Subsampling Approach. Applied Economics Letters, 17, 1145-1151. https://doi.org/10.1080/00036840902817581

[44] Fong, W.M. and Ouliaris, S. (1995) Spectral Tests of the Martingale Hypothesis for Exchange Rates. Journal of Applied Econometrics, 10, 255-271.

https://doi.org/10.1002/jae.3950100304

[45] Hong, Y. (1999) Hypothesis Testing in Time Series via the Empirical Characteristic Function: A Generalized Spectral Density Approach. Journal of the American Statistical Association, 94, 1201-1220. https://doi.org/10.1080/01621459.1999.10473874

[46] Hong, Y. and Lee, T.H. (2003) Inference on Predictability of Foreign Exchange Rates via Generalized Spectrum and Nonlinear Time Series Models. Review of Economics and Statistics, 85, 1048-1062. https://doi.org/10.1162/003465303772815925

[47] Kuan, C.M. and Lee, W.M. (2004) A New Test of the Martingale Difference Hypothesis. Studies in Nonlinear Dynamics \& Econometrics, 8, 1-24.

https://doi.org/10.2202/1558-3708.1191

[48] Escanciano, J.C. and Velasco, C. (2006) Generalized Spectral Tests for the Martingale Difference Hypothesis. Journal of Econometrics, 134, 151-185. https://doi.org/10.1016/j.jeconom.2005.06.019

[49] Escanciano, J.C. and Lobato, I.N. (2009) An Automatic Portmanteau Test for Serial Correlation. Journal of Econometrics, 151, 140-149.

https://doi.org/10.1016/j.jeconom.2009.03.001

[50] Lobato, I., Nankervis, J.C. and Savin, N.E. (2001) Testing for Autocorrelation Using a Modified Box-Pierce Q Test. International Economic Review, 42, 187-205. https://doi.org/10.1111/1468-2354.00106

[51] Horowitz, J.L., Lobato, I.N., Nankervis, J.C. and Savin, N.E. (2006) Bootstrapping the Box-Pierce Q Test: A Robust Test of Uncorrelatedness. Journal of Econometrics, 133, 841-862. https://doi.org/10.1016/j.jeconom.2005.06.014

[52] Chortareas, G., Jiang, Y. and Nankervis, J.C. (2011) The Random-Walk Behavior of the Euro Exchange Rate. Finance Research Letters, 8, 158-162. https://doi.org/10.1016/j.frl.2010.10.003 